\title{
Characterization and Modeling of Three-Dimensional Self-Healing Shape Memory Alloy-Reinforced Metal-Matrix Composites
}

\author{
Pingping Zhu ${ }^{1}$, Zhiwei Cui ${ }^{1}$, Michael S. Kesler², John A. Newman³, Michele V. \\ Manuel$^{2}$, M. Clara Wright ${ }^{4}$, L. Catherine Brinson ${ }^{1, *}$ \\ ${ }^{1}$ Mechanical Engineering, Northwestern University, Evanston, IL 60208 USA \\ ${ }^{2}$ Materials Science and Engineering, University of Florida, Gainesville, FL 32611 USA \\ ${ }^{3}$ NASA Langley Research Center, VA 23681 USA \\ ${ }^{4}$ NASA Kennedy Space Center, FL 32899 USA \\ * Corresponding author. E-mail: cbrinson@northwestern.edu
}

\begin{abstract}
In this work, three-dimensional metal-matrix composites (MMCs) reinforced by shape memory alloy (SMA) wires are modeled and simulated, by adopting an SMA constitutive model accounting for elastic deformation, phase transformation and plastic behavior. A modeling method to create composites with pre-strained SMA wires is also proposed to improve the self-healing ability. Experimental validation is provided with a composite under three-point bending. This modeling method is applied in a series of finite element simulations to investigate the self-healing effects in pre-cracked composites, especially the role of the SMA reinforcement, the softening property of the matrix, and the effect of pre-strain in the SMA. The results demonstrate that SMA reinforcements provide stronger shape recovery ability than other, non-transforming materials. The softening property of the metallic matrix and the pre-strain in SMA are also beneficial to help crack closure and healing. This
\end{abstract}


modeling approach can serve as an efficient tool to design SMA-reinforced MMCs with optimal self-healing properties that have potential applications in components needing a high level of reliability.

Key Words: Crack closure, Phase transformation, Pre-strain, Finite element model, Digital Image Correlation 


\section{Introduction}

Self-healing materials and material systems, exhibiting an ability to repair damage and recover functionality, comprise a new field that has advanced rapidly in recent years (Blaiszik et al., 2010; Chen et al., 2002; Ghosh, 2009; White et al., 2001). To date, most research conducted on self-healing materials has focused on selfhealing polymers (Chen et al., 2014; White et al., 2001; Wu et al., 2008) and ceramics (Madhan et al., 2012; Rebillat, 2014; Ruggles-Wrenn et al., 2014), while self-healing metals and metal composites have been less studied (Ferguson et al., 2015). In a series of seminal papers, Olson (Files et al., 1997), Manuel (Manuel et al., 2007), and co-workers (Bender et al., 2008) developed an approach for providing the self-healing property to metal-matrix composites (MMCs). The essential idea is to embed the shape memory alloy (SMA) reinforcements into specially engineered self-healing metal matrices. When a force is applied to a composite, it induces crack initiation and/or propagation, as well as phase transformation in the SMA wires. Since SMAs have the ability to recover their original shape even after significant deformation by applying heat above the transformation temperature of SMA, a reverse transformation takes place in the SMA and promotes shape recovery. Consequently, a recovery force is provided to the matrix, pulling the fracture surfaces together (Burton et al., 2006; Fremond, 1996). The matrices in turn are engineered to undergo a softening and partial liquefaction, to further enhance the closure and healing of the crack.

A proof-of-concept was developed for a self-healing SMA-reinforced Snbased MMC by Manuel in 2007 (Manuel et al., 2007). Based on this composite design, 
a liquid-assisted Shape Memory Alloy Self-Healing (SMASH) technology has been proposed that can be applied to other metal matrix materials (Fisher et al., 2013; Wright et al., 2013). This metal-metal composite system can be used in structures in high-stress locations where fatigue cracks tend to initiate, which can be particularly useful in aeronautical applications (Wright et al., 2013) or remote locations where replacement parts are unavailable. SMASH technology utilizes both the shape memory property of SMA reinforcements and liquid-assisted healing of the metal matrix. Upon heating the MMC system with cracks generated from loading, the reverse transformation in the SMA promotes the MMC to shrink and close the crack surfaces. Meanwhile, at the elevated temperature, the matrix becomes partially molten and acts as a healing agent to reshape, fill and heal the crack. Upon returning to room temperature, the matrix solidifies fully and the SMA retains in its original shape. Thus, the crack in the SMA-reinforced MMC is healed without applying external forces. The feasibility of this liquid-assisted SMASH technology has been previously demonstrated (Ferguson et al., 2015; Manuel et al., 2007; Nosonovsky et al., 2011). Since this method enables repeatable usage of the healing agent, damage could be repaired multiple times over the lifetime of the structure.

In parallel with the proof-of-concept, some efforts have been dedicated to investigate the modeling of self-healing SMA-reinforced composite structures. In general, micromechanics and finite elements are the two major approaches used in the previous studies (Araki et al., 2002; Bor et al., 2010; Burton et al., 2006; Kawai et al., 1999). Micromechanical approaches can capture the behavior of a representative microstructure very well, but they are not easily applicable at the structural scale. 
On the other hand, finite element (FE) approaches employ phenomenological descriptions and enable fast computation for engineering components, which are preferable for macroscopic structures. One FE approach is to develop special composite elements (Marfia et al., 2003; Zak et al., 2003), while another more flexible approach is to model the reinforcement and matrix separately. In the latter approach, previous studies have mostly adopted one-dimensional constitutive models of the SMAs (Burton et al., 2006; Sharma et al., 2008). Though onedimensional constitutive models can capture the uniaxial behavior, they fail to characterize the non-uniaxial performance. Another key drawback of most existing constitutive models is that they have not considered all the major properties or mechanical behaviors of SMAs, such as reorientation, self-accommodated martensite (Lee et al., 2000), or plasticity (Burton et al., 2006). To address these issues, a number of three-dimensional phenomenological constitutive models of SMAs have been developed (Peng et al., 2012; Popov et al., 2007; Zhu et al., 2014). In this work, we use, as a base, the Stebner-Brinson model (Stebner et al., 2013), and, specifically, an improved SMA model that accounts for elasticity, orientation (phase transformation between austenite and martensite), reorientation (transformation among the various states of martensite), as well as plasticity (Zhu et al., 2014). The implementation of this model is achieved by developing a user subroutine VUMAT to adapt Abaqus/Explicit. By applying this SMA model, this work proposes a modeling method for three-dimensional self-healing SMA-reinforced MMC structures. 
The remainder of the paper is organized as follows: in Section 2, we briefly introduce the three-dimensional SMA constitutive model; in Section 3, the finite element modeling strategy and experimental validation of the self-healing composites is presented with results and discussion in Section 4, followed by conclusions.

\section{Three-Dimensional SMA Constitutive Model}

The constitutive model of the SMA used in this study is a recently developed implementation of the Stebner-Brinson model (Zhu et al., 2014), a threedimensional constitutive model that incorporates elastic deformation, orientation (phase transformation), reorientation, as well as plasticity. In self-healing composites, local stresses near inclusions and crack tips can be quite high, indicating that plastic deformation cannot be neglected.

According to this constitutive model, strain is composed of elastic, orientation, reorientation, and plastic parts. The sum of the orientation, reorientation and plastic strains is also called the inelastic strain. The relation of the strains can be written as

$$
\boldsymbol{\varepsilon}=\boldsymbol{\varepsilon}_{e}+\boldsymbol{\varepsilon}_{i n}=\boldsymbol{\varepsilon}_{e}+\boldsymbol{\varepsilon}_{\sigma}+\boldsymbol{\varepsilon}_{r e}+\boldsymbol{\varepsilon}_{p l}
$$

where the superscripts $e, \sigma, r e$ and $p l$ represent elastic, orientation, reorientation, and plastic terms, respectively. 
The martensitic volume fraction $\xi$ is the sum of two variables, $\xi_{\sigma}$ and $\xi_{S A}$, denoting oriented $(\sigma)$ and self-accommodated $(S A)$ martensitic volume fraction, respectively. $\xi, \xi_{\sigma}$ and $\xi_{S A}$ should all lie in the range between 0 to 1 .

The model is formulated based on the expression of the Helmholtz free energy and the second law of thermodynamics, which is then written in the form of the Clausius-Duhem inequality as (Panico et al., 2007)

$$
\rho D_{p}=\boldsymbol{X}_{\sigma}: \boldsymbol{\varepsilon}_{\sigma}+\boldsymbol{X}_{r e}: \boldsymbol{\varepsilon}_{r e}+X_{S A} \boldsymbol{\xi}_{S A}+\boldsymbol{X}_{p l}: \boldsymbol{\varepsilon}_{p l} \geq 0
$$

in which $\rho$ is the material density, and $D_{p}$ the dissipation potential, and four driving forces $(X)$ are defined as

$$
\begin{aligned}
& \boldsymbol{X}_{\sigma}=\boldsymbol{\sigma}^{\prime}-\frac{\rho\left(\left\langle T \tilde{\eta}_{0}-\tilde{\mu}_{0}\right\rangle+H_{\sigma} \xi_{\sigma}\right)}{\sqrt{3 / 2} \varepsilon_{\max }} \boldsymbol{N}\left(\boldsymbol{\varepsilon}_{t r}\right) \\
& \boldsymbol{X}_{r e}=\boldsymbol{\sigma}^{\prime} \\
& X_{S A}=-\rho\left(T \tilde{\eta}_{0}-\tilde{\mu}_{0}\right) \\
& \boldsymbol{X}_{p l}=\boldsymbol{\sigma}^{\prime}-\overline{\boldsymbol{\beta}}
\end{aligned}
$$

where $\sigma^{\prime}$ is the deviatoric stress, $T$ is temperature, $\varepsilon_{\max }$ is the maximum transformation strain, $H_{\sigma}$ is a material parameter governing the hardening of transformation (Panico et al., 2007), $N\left(\varepsilon_{t r}\right)$ is the norm unit of transformation strain, $\tilde{\eta}_{0}$ and $\tilde{\mu}_{0}$ are specific energy and entropy (Stebner et al., 2013) respectively, and $\overline{\boldsymbol{\beta}}$ is the back stress (Zhu et al., 2014).

The evolution equations are: 


$$
\begin{aligned}
& \dot{\boldsymbol{\varepsilon}}_{\sigma}=\dot{\lambda}_{\sigma} \boldsymbol{X}_{\sigma} \\
& \dot{\boldsymbol{\varepsilon}}_{r e}=\dot{\lambda}_{r e} \underline{\underline{\underline{I}}}\left(\boldsymbol{\varepsilon}_{r e}\right): \boldsymbol{X}_{r e} \\
& \dot{\xi}_{S A}=\dot{\lambda}_{S A} X_{S A} \\
& \dot{\boldsymbol{\varepsilon}}_{p l}=\dot{\lambda}_{p l}=\sqrt{\frac{2}{3}} \frac{1}{2 \mu\left(1+\frac{K}{3 \mu}\right)}\left(\left(\boldsymbol{\sigma}^{\prime}-\overline{\boldsymbol{\beta}}\right):\left(\boldsymbol{\sigma}^{\prime}-\overline{\boldsymbol{\beta}}\right)^{1 / 2}-\frac{2}{3} \sigma_{0}\right)
\end{aligned}
$$

in which $\dot{\varepsilon}_{p l}$ denotes the magnitude of the increment of plastic strain tensor, $\dot{\lambda}$ denotes Lagrange multipliers, $\underline{\underline{\underline{I}}}$ is a fourth-order tensor that projects its transverse part (Belytschko et al., 2013), $K$ is plastic hardening coefficient, $\mu$ is the Lame parameter, and $\sigma_{0}$ is the uniaxial equivalent yield stress.

Kinetic relations are introduced by the limit functions $(F)$ :

$$
\begin{aligned}
& F_{\sigma}=\left\|\boldsymbol{X}_{\sigma}\right\|-Y_{\sigma}\left(\xi_{\sigma}\right) \\
& F_{r e}=\left\|\underline{\underline{\underline{I}}}\left(\boldsymbol{\varepsilon}_{t r}\right): \boldsymbol{\sigma}^{\prime}\right\|-Y_{r e} \\
& F_{S A}=X_{S A}-Y_{S A}\left(\xi_{S A}\right) \\
& F_{p l}=\left\|\boldsymbol{\sigma}^{\prime}-\overline{\boldsymbol{\beta}}\right\|-\sigma_{0}
\end{aligned}
$$

which satisfy the Kuhn-Tucker conditions:

$$
F_{\alpha} \leq 0 ; \quad \Delta \lambda_{\alpha} \geq 0 ; \quad \Delta \lambda_{\alpha} F_{\alpha}=0
$$

where subscript $\alpha$ takes on the values $\alpha=\sigma, r e, S A, p l . Y_{\alpha}$ in Eqs. (5) represent kinetic equations used to determine the state of the SMA (orientation, reorientation, plasticity, etc.)

During the computation, the total strain, $\varepsilon$, and temperature, $T$, are chosen as control variables. In each step, for every $\varepsilon$ and $T$, the limit function of plasticity is evaluated first, and if not satisfied, the calculation proceeds in the order of reorientation, orientation and self-accommodation. In these modules, the stress, 
strain and martensitic volume fractions will be updated based upon the aforementioned equations and algorithms. Figure 1 displays a detailed flowchart of this algorithm, and more details can be found in the literature (Zhu et al., 2014). It is also noted here that orientation, reorientation, self-accommodation and plasticity are assumed to behave independently in this paper. Accordingly, a user subroutine VUMAT code is programmed, which is then implemented into Abaqus/Explicit (Abaqus, 2010).

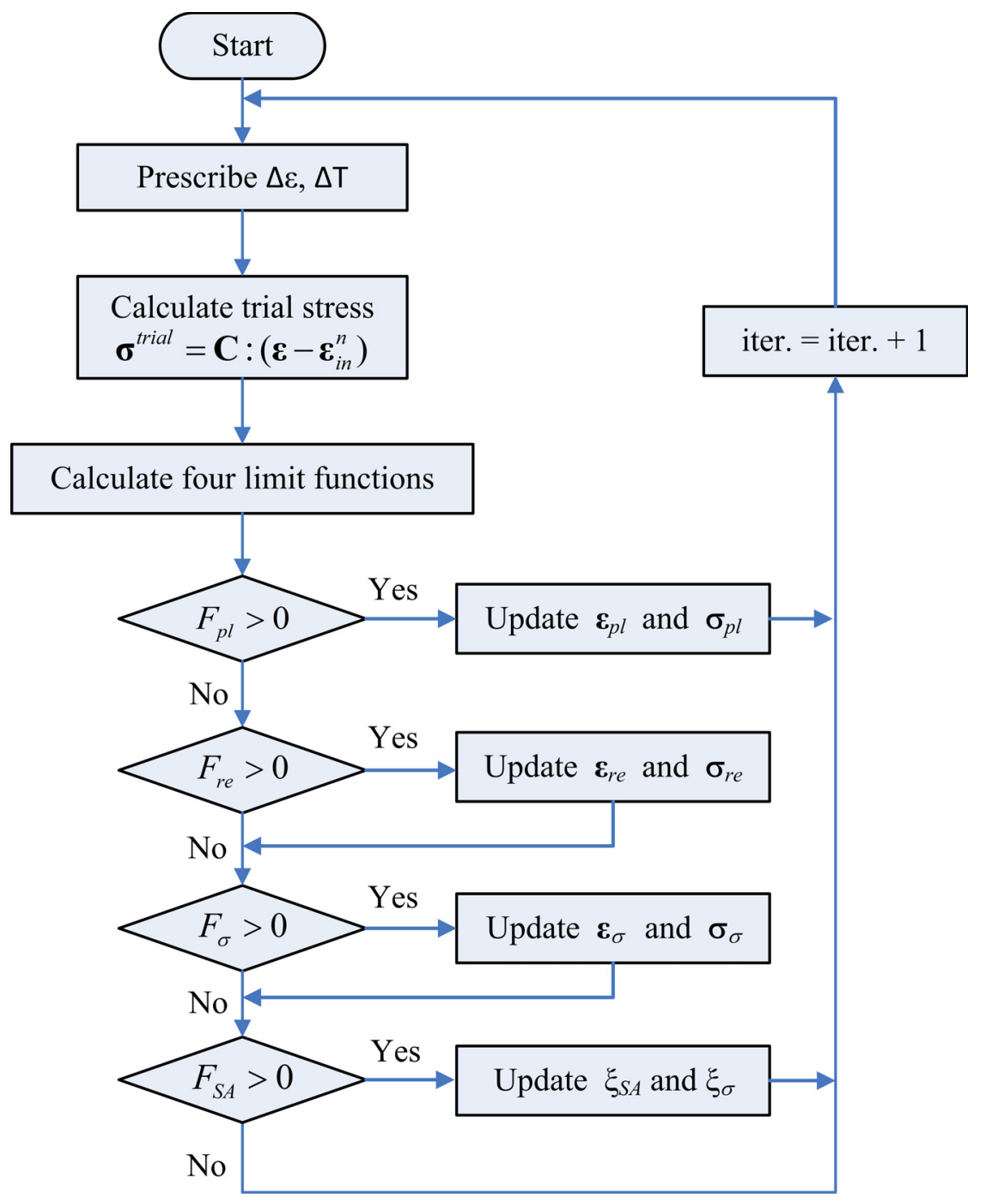

Figure 1 Algorithm of the elastic-transformation-plastic model 


\section{Finite Element Model and Validation}

In this section, a finite element model is introduced to represent a three point bending composite, which is tested and used as validation of the approach. The simulations are also used to consider composite system with pre-strained SMA wires, which allows the crack closure of fractured composites to be further enhanced.

\subsection{Prototype three-point bending beam: Experiment}

In this study, a three-point bending beam made of a self-healing $\mathrm{Sn}-22 \mathrm{at} \% \mathrm{Bi}$ alloy matrix and NiTi SMA reinforcement wires in the pseudo-elastic condition is tested (Figure 2(a)). Bars of Sn-22at\%Bi with SMA reinforcement were fabricated by casting. The matrix was comprised of $99.99 \%$ pure Sn and Bi purchased from Alfa Aesar. The NiTi wires, manufactured by Memry Corporation, were $0.87 \mathrm{~mm}$ in diameter and in the pseudo-elastic condition. A rectangular graphite mold was designed with removable sides that can be threaded with SMA wires. The molten matrix material was poured into the mold from one end such that the SMA wires did not bow. The key properties of the reinforcement and matrix will be elaborated in the modeling part in Section 3.2. The test specimen is $100 \mathrm{~mm}$ long, $30 \mathrm{~mm}$ wide, and 25mm deep. As displayed in Figure 2(a), a single-edge notch (SEN) with a depth of $2.5 \mathrm{~mm}$ is fabricated using a band saw and then a X-Acto saw. The notch width at the base of the single edge notch is $0.3 \mathrm{~mm}$. The specimens were fatigue pre-cracked to 7.6mm prior to bending. Eight SMA wires in four depths are placed parallel along 
the beam length, $8.5 \mathrm{~mm}$ away from the top or bottom in height, and $5 \mathrm{~mm}$ distance from each other. Bending fixtures are placed on the top center and bottom outer spans of the beam for three-point bending.

Mechanical testing was conducted on an Instron 5582 load frame at ambient and elevated temperatures. To characterize the matrix properties, tensile testing of Sn-22at\%Bi dog bones, following ASTM E8 standard subsize specimens (ASTM, 2000), were performed at a constant displacement rate of $3 \times 10^{-2} \mathrm{~mm} / \mathrm{s}$. Bending tests of the composite were performed at a constant displacement rate of $5 \times 10^{-3}$ $\mathrm{mm} / \mathrm{s}\left(5 \times 10^{-5} \mathrm{~mm} / \mathrm{mm} \cdot \mathrm{s}^{-1}\right)$. Three-point bending fixtures with $10 \mathrm{~mm}$ rollers and a span of $100 \mathrm{~mm}$ were used along with a bolt-on knife edge Epsilon 3541 clip-on extensometer for measuring crack opening displacement (COD). The bending specimens were loaded to a nominal COD of $0.25 \mathrm{~mm}$, then unloaded and the final COD was recorded. Additionally, Digital Image Correlation (DIC) data was collected to provide strain maps which are compared to simulated strain maps. 
(a)

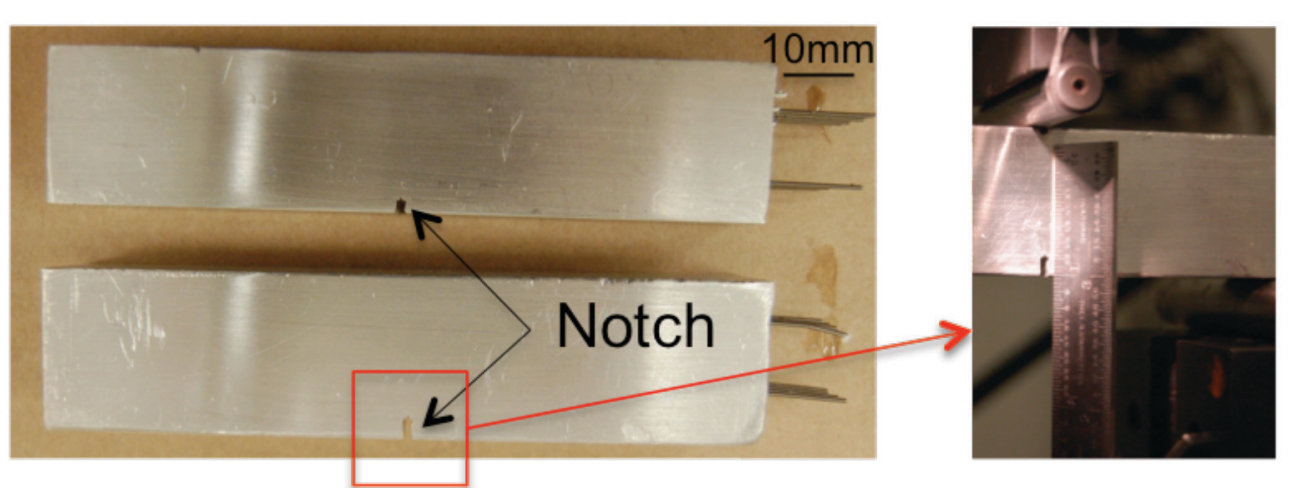

(b)

(c)

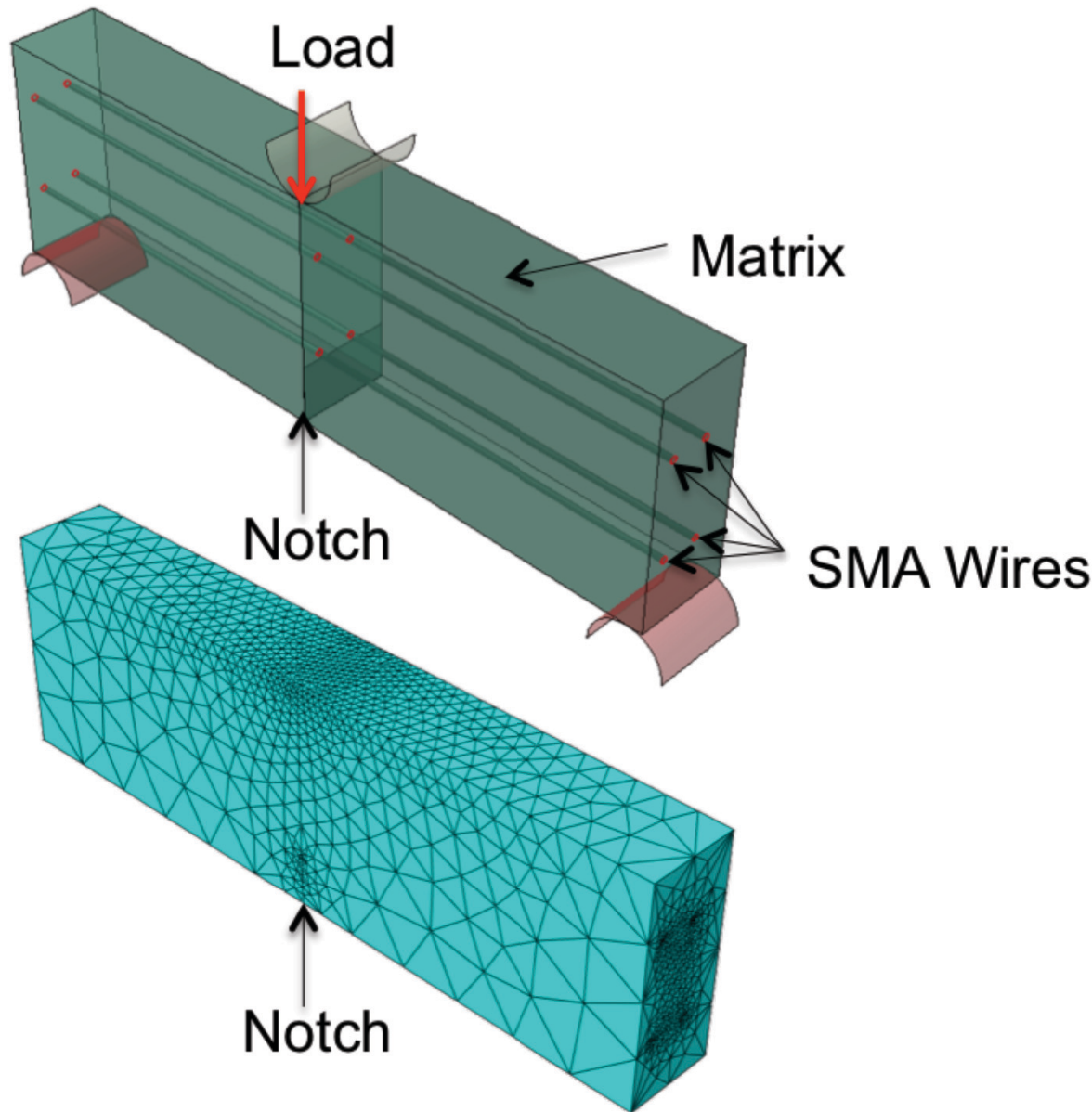

Figure 2 Schematic of the three-point bending beam (a) full test specimen (b) geometry of the half model (c) mesh of the half model

3.2 Prototype three-point bending beam: Model 
The finite element model is created following the size and loading conditions of the experiment. A half model is created in Abaqus due to symmetry, so the model depth is $12.5 \mathrm{~mm}$ as displayed in Figure 2(b). A V-notch of $7.6 \mathrm{~mm}$ is pre-defined in the model. Four SMA wires are placed parallel along the beam length in two layers due to symmetry. A circular arc-shaped rigid body is modeled on the top center and bottom outer span of the beam to simulate the bending fixtures used in the test.

The reinforcement and matrix are modeled separately in Abaqus, and no special element is used in this modeling method, allowing easy iteration on simulations since the material properties can be modified independently without changing the geometry. A VUMAT describing the SMA behavior is implemented into Abaqus for computation. The material properties and kinetic tuning parameters used for NiTi are listed in Table 1. To determine the parameters, calibration is performed to a set of experimental data. The parameters are defined as unknowns in the model, which are then tuned to make the simulated stress-strain curve on a monolithic SMA element as close as to the experimental data.

Table 1 Material properties and kinetic tuning parameters of NiTi in the simulation

\begin{tabular}{|c|c|c|c|}
\hline Property & Value & Parameter & Value \\
\hline Elastic Modulus, $E(\mathrm{GPa})$ & 67.9 & $\begin{array}{c}\text { Reorientation Onset } \\
\text { Parameter, } Y_{r e}(\mathrm{MPa})\end{array}$ & 500 \\
\hline Poisson's Ratio, $v$ & 0.33 & Transformation Hardening & 600 \\
\hline
\end{tabular}




\begin{tabular}{|c|c|c|c|}
\hline & & Parameter, $H_{\sigma}(\mathrm{J} / \mathrm{kg})$ & \\
\hline Density, $\rho\left(\mathrm{g} / \mathrm{cm}^{3}\right)$ & 6.5 & Forward Transformation & 250 \\
& & Onset Parameter, $C^{f}$ (MPa) & \\
\hline Martensite Start & 276 & Reverse Transformation & 30 \\
Temperature, $M_{s}(\mathrm{~K})$ & & Onset Parameter, $C^{r}$ (MPa) & \\
\hline Martensite Finish & 259 & Transformation Hardening & 0 \\
Temperature, $M_{f}$ (K) & & Parameter, $A^{r}$ (MPa) & \\
\hline Austenite Start & 267 & Plastic Hardening & 12 \\
Temperature, $A_{s}(\mathrm{~K})$ & & Coefficient, $K$ (GPa) & \\
\hline Austenite Finish & 284 & & \\
Temperature, $A_{f}(\mathrm{~K})$ & & & \\
\hline Clausius-Clapeyron & 10.0 & & \\
Coefficient, $C_{A, M}$ (MPa/K) & & & \\
\hline Maximum Transformation & 0.08 & & \\
\hline Stain, $\varepsilon_{\text {max }}$ & & & \\
\hline Yield Strength, $\sigma_{0}(\mathrm{MPa})$ & 500 & & \\
\hline
\end{tabular}

The simulated matrix adopts Sn-22at\%Bi properties, including temperaturedependent softening as presented in Table 2, which were performed via tensile tests. The matrix properties follows bilinear elastic-plastic laws at the temperatures listed, and are interpolated between these temperatures and extrapolated at 
temperatures above 398K. All of the tensile tests for the matrix material were stopped after significant load drop and necking, and none actually fully fractured during the testing. Thermal expansion is negligible compared to the shape memory effect and is not considered in the simulation. The reinforcement and matrix are assumed to bond with each other in a perfect manner.

Table 2 Material properties of the Sn-22at\%Bi matrix material at elevated temperatures from $296 \mathrm{~K}$ to $398 \mathrm{~K}\left(23^{\circ} \mathrm{C}\right.$ to $125^{\circ} \mathrm{C}$ )

\begin{tabular}{|c|c|c|c|c|}
\hline Temperature (K) & 296 & 348 & 373 & 398 \\
\hline Yield Strength, $\sigma_{0}$ & 64 & 46.4 & 30.4 & 17.3 \\
\hline $\begin{array}{c}\text { Elastic Modulus, } \\
\text { E (GPa) }\end{array}$ & 32.8 & 22 & 19 & 9.2 \\
\hline $\begin{array}{c}\text { Ultimate Tensile } \\
\text { Strength (UTS), }\end{array}$ & 81 & 55 & 36 & 19 \\
$\sigma_{\text {UTS }}$ (MPa) & & & & \\
\hline $\begin{array}{c}\text { Strain } \\
\text { corresponding to }\end{array}$ & 0.01 & 0.01 & 0.01 & 0.0067 \\
the UTS \\
(mm/mm)
\end{tabular}

To simulate the experimental conditions, the load path is composed of three steps: 1) a vertical displacement controlled load is prescribed at room temperature. 
At the same time the COD at the bottom face is measured and when it reaches 0.25 $\mathrm{mm}, 2$ ) then the load is removed. After load removal the composite is 3) heated to 442K. This load path is illustrated in Figure 3 (a), in which the nonlinear force and temperature profiles are displayed versus time. The matrix is designed to be $20 \%$ liquid at the healing temperature. It is noted that while softening is incorporated in the simulation, the partial liquefaction of the matrix is not included.

\subsection{Validation of the prototype three-point bending beam}

The COD is first measured for validation since it is a key measurable quantity in the experiment, while many other quantities such as extent of phase transformation and plasticity maps are difficult to obtain via experimental tests. From the test data, the COD after unloading is $0.15 \mathrm{~mm}$, and the value after heating is not measured due to some other factors that may complicate the validation. The measured COD after unloading agrees closely with the computed value of $0.14 \mathrm{~mm}$, shown in Figure 3 (b). This comparison of the COD at the loading and unloading stages provides a promising validation of the modeling methodology. 
(a)

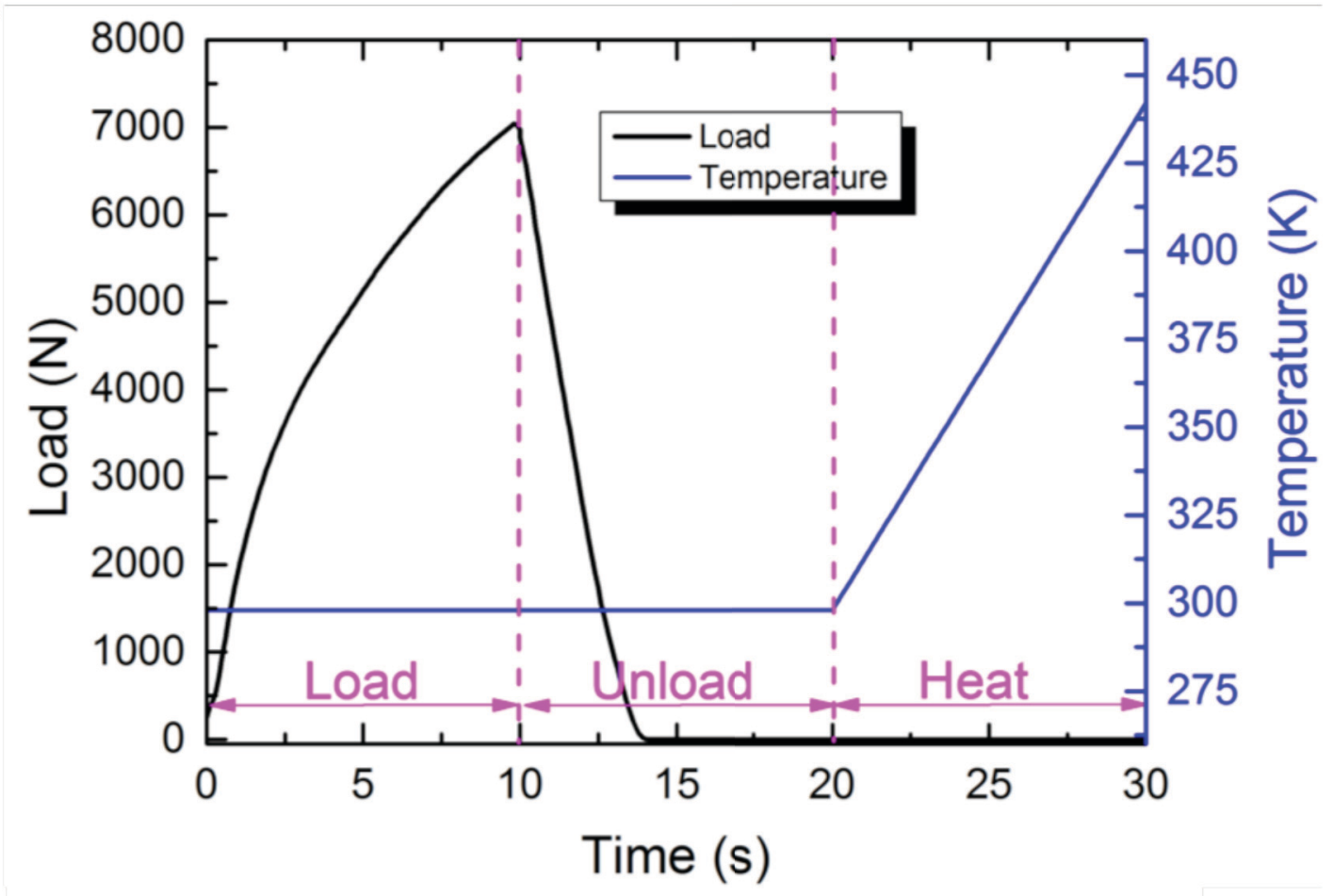

(b)

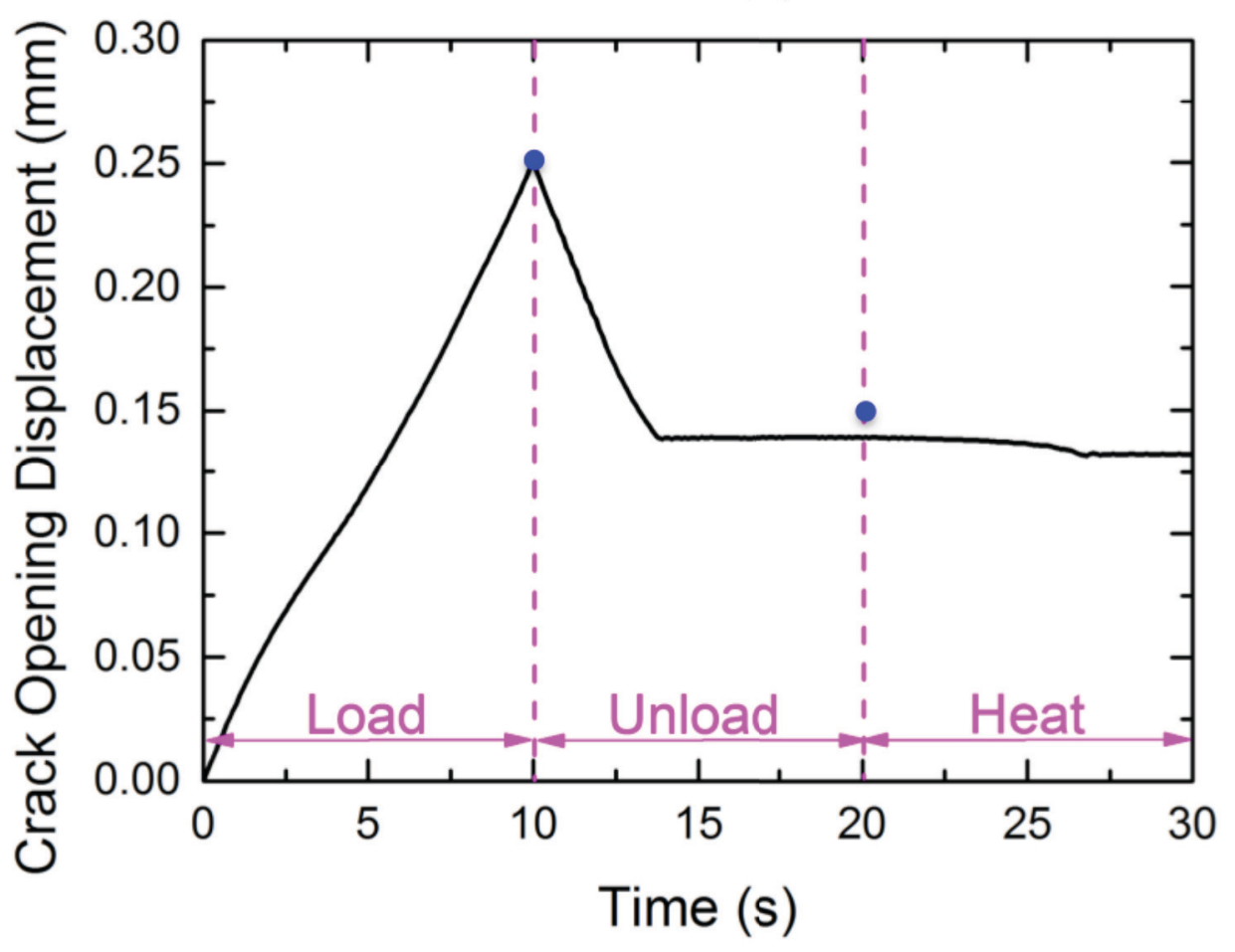




\section{Figure 3 Simulation details of the prototype three-point bending beam. (a) load and temperature versus time; (b) computed crack opening displacement (the solid line) and experimental test data (the large dots).}

Another validation is performed by comparing the axial strain maps obtained from simulation and DIC, respectively. As is displayed in Figure 4, in both simulation and experiment, higher strain is found at the crack tip area at the end of loading, which is caused by the sharp stress concentration. The localized strain is a little higher in DIC test result than that in the simulation, which is due to the different shapes of the crack tip in the test specimen and in the simulation model. As mentioned earlier, the test specimen adopts blunt single-edge notch with a sharp fatigue pre-crack, which contains a large width between the crack faces (the large black area in Figure 4(b)) and a very thin sharp crack leading from that large separation; while the simulation model uses a V-notch with straight lines and sharp corner. It is also noted that the experimental sample has small lobes at the end of blunt wide crack before the sharp crack begins - it is likely that these features of the blunt crack lead to the tilted lobes of the strain concentrations ahead of the sharp crack in the experimental sample. Nevertheless, the size and shape of the high strain area are very similar in overall in the two strain maps, while the difference in the contour profiles is also ascribed to the distinct crack shapes. The scale bars are set to be comparable for the simulation contour and DIC plot, and similar scale is also found. Therefore, the DIC test serves as another sound validation for the modeling approach. 
In addition, it is noticeable in the strain field in Figure 4 that the crack tip has experienced some plastic deformation. This plastic strain field is the major reason for the incomplete crack closure upon unloading as shown in Figure 3. For both SMA reinforcement and Sn-22at\%Bi matrix, the unrecoverable plastic strain prevents the crack from full recovery during healing.

\section{(a) Simulation Result}
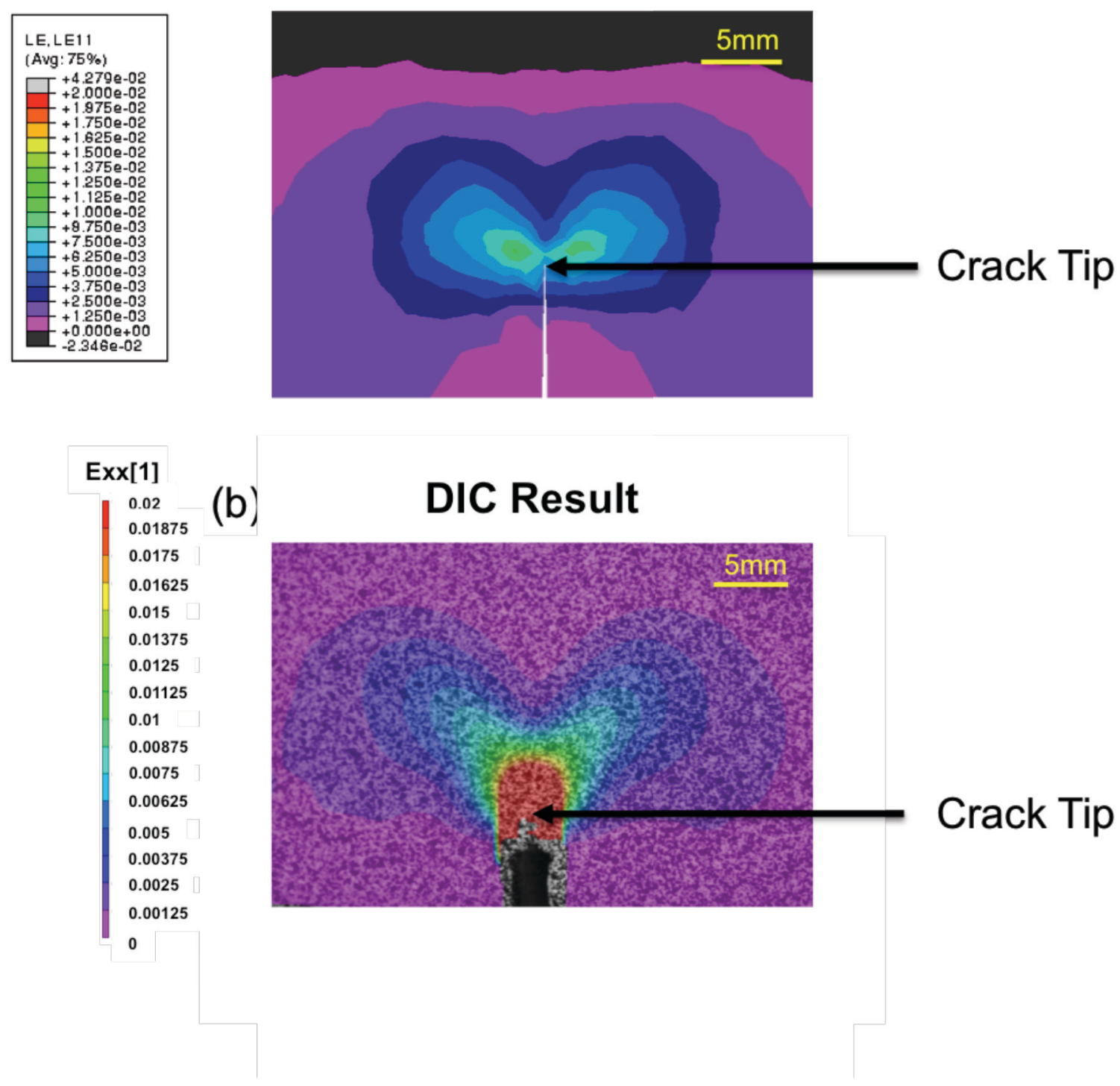


\section{Figure 4 Axial strain maps around the crack tip in (a) simulation and (b) DIC test at the end of loading (COD $=0.25 \mathrm{~mm})$}

\section{4 Modeling of composite with pre-strained SMA wires}

To further improve the self-healing property of SMA-reinforced composites, we hypothesize that use of pre-strained SMA wires, which undergo the thermal shape memory effect response, in the composite would be advantageous. While experiments have not yet incorporated this option, it demonstrates the potential of the simulations to optimize material design before testing. In the simulations, SMA wires are first stretched from self-accommodated martensite, and then unloaded to zero stress state. Since there is no reverse transformation from oriented martensite to self-accommodated martensite, the deformation is not yet recovered, and a prestrain remains in the stress-free wires. The pre-strained SMA wire is then embedded into the matrix to fabricate a composite.

Since it is not straight-forward to directly create a composite with prestrained materials in Abaqus/Explicit, we develop a method to define the pre-strain in the user subroutine VUMAT. In addition, the initial phase compositions of selfaccommodated and oriented martensite are also determined by running preparatory simulations of a single SMA wire undergoing a given pre-load. The obtained pre-strain and phase states are adopted as initial conditions in the FE model of the composite. This modeling approach allows easy consideration of different pre-strains. It is demonstrated that a pre-strained SMA wire can play a significant role in crack closure. 


\section{Results and Discussion}

In this section, a FE model with the three-point bending setup, as introduced in Section 3.2, is adopted. A vertical displacement of $1.5 \mathrm{~mm}$ is applied in the first loading step, while the later steps follow the descriptions in Section 3.2. Based on the prototype model, three series of simulations are performed to illustrate the role of 1) the SMA wire, 2) the temperature-softening matrix, and 3) the pre-strain in SMA wires, respectively.

\section{1 Effect of varying reinforcements on crack closure}

The first set of simulation models has the same geometry as the prototype three-point bending composite beam, and varying reinforcement materials are employed. Four metals are considered for the reinforcement to compare the crack closure and self-healing effects. In addition to SMAs, the materials used as reinforcement include a $\mathrm{Sn}-22 \mathrm{at} \% \mathrm{Bi}$ alloy, which is the same material as the matrix serving as a control case; a steel with bilinear elastic-plastic behavior (see Table 3); and a hypothetical material with the same elastic and plastic behaviors as SMA, but without the phase transformation ability. In addition, a composite with $1.6 \%$ prestrained SMA wires is also simulated. Summarization of the five different numerical cases performed is presented in Table 4. These five composite structures with the same geometric configuration, load steps, and boundary condition are simulated in Abaqus, with the results displayed in Figure 5. The crack opening displacements are compared in these structures during loading, unloading and heating. Results 
demonstrate that the composites with the SMA reinforcement have greater crack closure and therefore will likely facilitate stronger self-healing ability, compared to the other reinforcements. In particular, the one with pre-strained SMA displays the largest crack closure behavior. This result is due to the phase transformation property of the SMA, which plays a part in the shape recovery and crack closure in the structures. The structures made of other reinforcements also exhibit some recovered deformation after heating, which is a result of the elastic response of the wires during the softening of the Sn-Bi matrix with temperature. The structure with steel wire reinforcement resulted in the smallest amount of crack closure, since the modulus of steel is much larger than SMA and Sn-Bi and the resulting recoverable elastic strain from a specific stress level is smaller. There are cusps in all the curves in the heating stage, which indicate that the matrix yields at the corresponding temperature. Since plastic yielding prevents shape recovery and crack closure, the COD curves flatten after the cusps. However, when further increasing the temperature, the stress in the matrix drops below the yielding strength again, and the slopes of the curves steepen. In brief, from the study of varying reinforcement materials, it is found the phase transformation property of SMA has a positive influence in driving crack closure.

\section{Table 3 Material properties of steel in the simulation}

\begin{tabular}{|c|c|}
\hline Property & Value \\
\hline Elastic Modulus, E (GPa) & 200 \\
\hline
\end{tabular}




\begin{tabular}{|c|c|}
\hline Density, $\rho_{\left(\mathrm{g} / \mathrm{cm}^{3}\right)}$ & 8.05 \\
\hline Yield Strength, $\sigma_{0}(\mathrm{MPa})$ & 250 \\
\hline Ultimate Tensile Strength (UTS), $\sigma_{\text {UTS }}$ & 400 \\
$(\mathrm{MPa})$ & \\
\hline Strain corresponding to the UTS \\
$(\mathrm{mm} / \mathrm{mm})$
\end{tabular}

Table 4 Reinforcement materials of the five different numerical cases

\begin{tabular}{|c|c|c|}
\hline & Reinforcement & Reinforcement Properties \\
\hline Case 1 & Regular SMA & E=67.9 GPa, \\
& & K=12 GPa, \\
& & Transformation properties in \\
& & Table 1 \\
& Sn-22at\%Bi alloy & E=32.8 GPa at 296K, \\
& (same as the matrix) & More properties in Table 2 \\
\hline Case 2 & Elastic-plastic steel & E=200 GPa, \\
& Case 3 & More properties in Table 3 \\
& Hypothetical material & E=67.9 GPa, \\
& similar to SMA (same & K=12 GPa, \\
& elastic and plastic & No transformation property \\
& properties, but no & \\
\hline Case 4 & & \\
\hline
\end{tabular}




\begin{tabular}{|c|c|c|}
\hline & $\begin{array}{r}\text { phase transformation } \\
\text { ability) }\end{array}$ & $\mathrm{E}=67.9 \mathrm{GPa}$, \\
& $\mathrm{K}=12 \mathrm{GPa}$, \\
Case 5 & Transformation properties in \\
& Table 1 \\
& Pre-strain $=1.6 \%$ \\
\hline
\end{tabular}

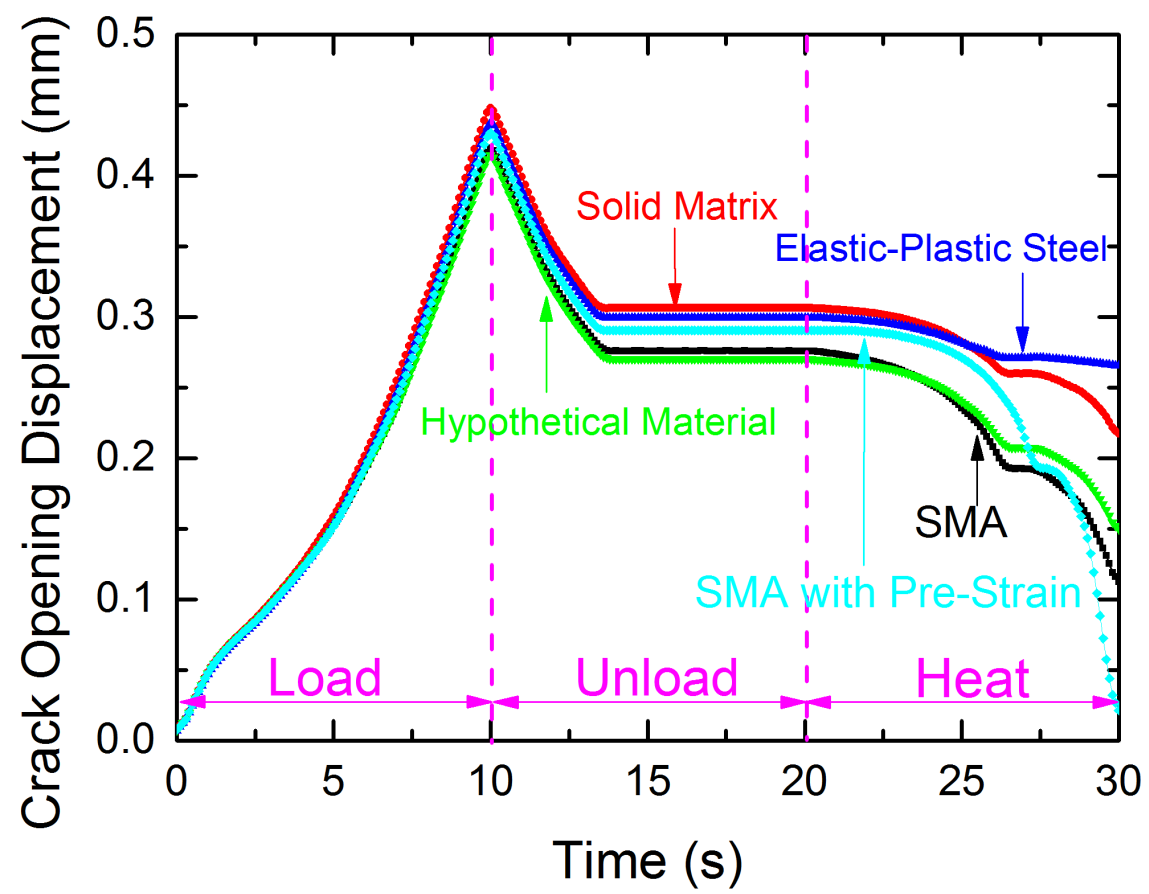

Figure 5 Crack opening displacement in the three-point bending beam with varying reinforcement materials. The "hypothetical material" indicates a material with the same properties as the SMA but without phase transformation 


\subsection{Effect of varying temperatures on crack closure}

The determination of healing temperature is a great concern in designing a SMA-reinforced MMC. For a free standing SMA, as long as the healing temperature is higher than the critical transformation temperature corresponding to the subjected load, all the transformation strain can be fully recovered (Brinson, 1993). The Sn-Bi matrix possesses a softening behavior that increases with temperature, described in Table 2. This temperature-dependent softening enables mitigation of the localized plasticity caused by loading in the matrix, and therefore can help the structure to recover more deformation. To illustrate this point, in Figure 6, the influence of varying temperatures on the self-healing property is investigated. In the prototype model, a healing temperature of $442 \mathrm{~K}$ was adopted, and for comparison, lower healing temperatures of $370 \mathrm{~K}$ and $400 \mathrm{~K}$ are also considered. In each model, the temperature is increased gradually from room temperature to the healing temperature at an even pace, so the heating rate varies in the three models. Note that the time scale in Figure 6 is a parameter which tracks the current load or temperature of the material (see Figure 3). It can be concluded from the simulation results that higher temperature promotes greater crack closure due to increased softening, which is beneficial for self-healing. The flat line at the end of the $400 \mathrm{~K}$ curve is caused by the plasticity at the corresponding temperature, which is mentioned in Section 4.1. Actually the COD after heating is only dependent on the temperature, instead of any other factors such as heating rate, time, etc. For example, the plateau seen in the green curve in Figure 6 at 27 sec corresponds to the 
plateau of the red curve at $30 \mathrm{sec}$. The final CODs in Figure 6 will not decrease any further even though we hold for longer time at the constant healing temperature.

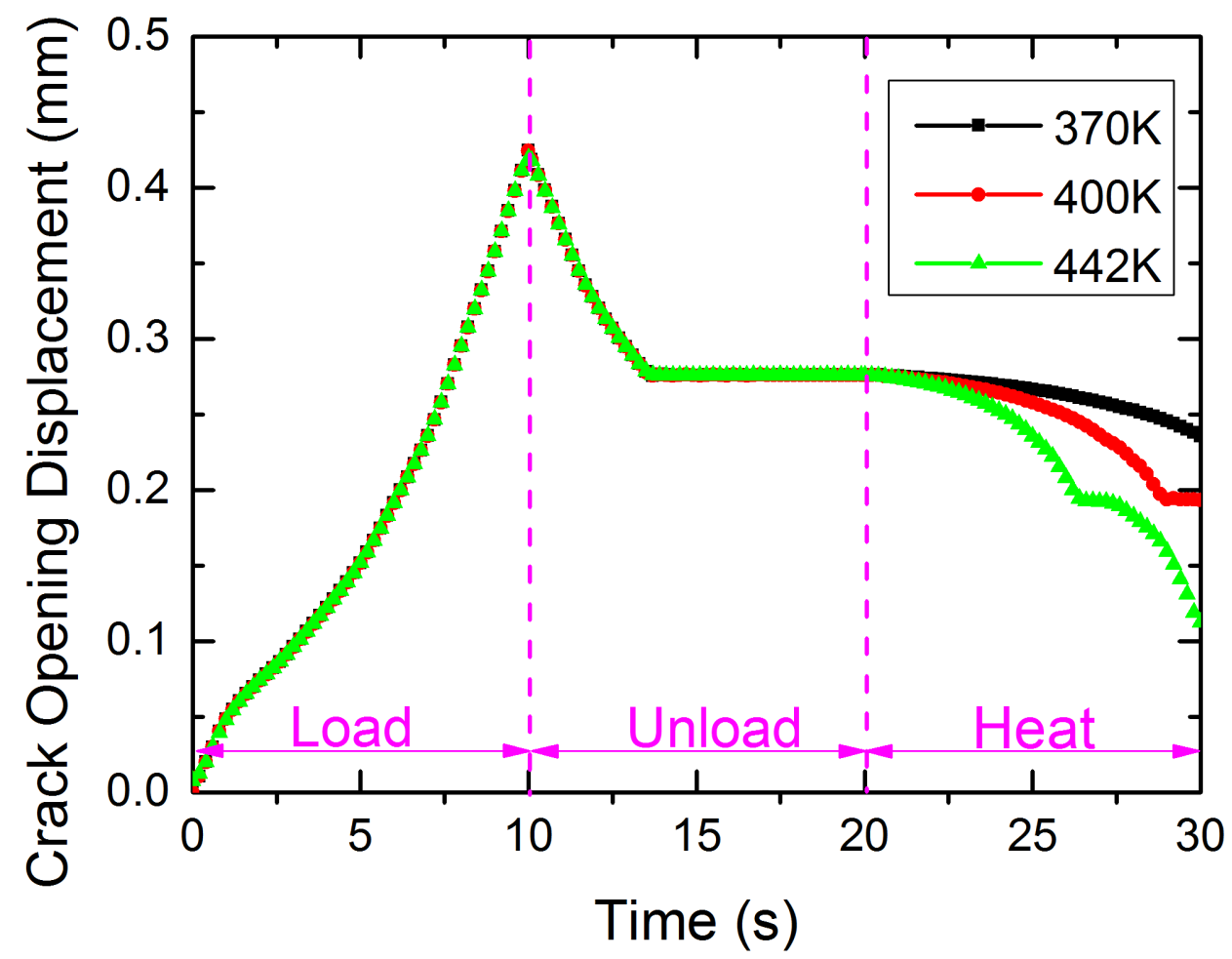

Figure 6 Crack opening displacement in the three-point bending beam with varying healing temperatures

\section{3 Effect of varying pre-strain in SMA wire on crack closure}

In most of the previous models in this section, SMA wires are stress and strain-free in the composites before loading. However, from the simulation result as revealed in Figure 5 and Figure 6, the final crack opening displacements in those composites are larger than zero, which indicates that the crack can not be fully closed after heating, which is also observed in the experiment as stated earlier where the final COD in Figure 5 agrees well with the experimental value for the 
black SMA curve (no pre-strain). This incomplete crack closure in the composites is due to the plasticity in the reinforcement and/or matrix upon loading (Figure 7). The first row in Figure 7 shows the plastic strain in the matrix (a) after loading and (b) after heating. The plastic regions, illustrated by the gray color in the figures, are observed in the vicinity of the crack, at the top center of the beam where load is applied, and at the bottom ends near the supporting rollers due to stress concentration. The maximum local plastic strain reaches as high as about $8 \%$ and remains during the unloading step. The plastic strain distributions are nearly identical before and after heating, as well as with and without pre-strain, since recrystallization of matrix is not considered in the simulation. In the experimental sample, the partial liquefaction of the matrix at the highest temperatures leads to softening and the removal of the dislocations associated with plasticity (recovery and recrystallization of grain structures). This matrix plasticity healing is not included in the current simulation as it does not significantly impact the crack opening or closure, but this effect would lead to better performance of the composite upon reloading due to the healing of the plastic matrix strain. 


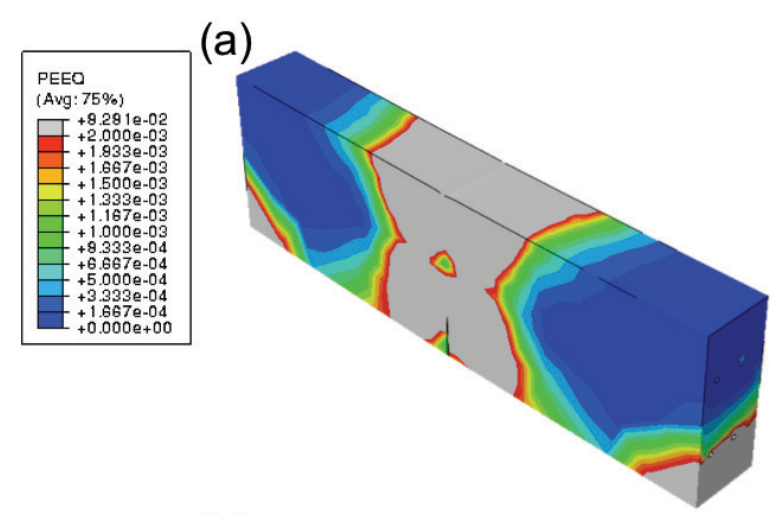

(b)

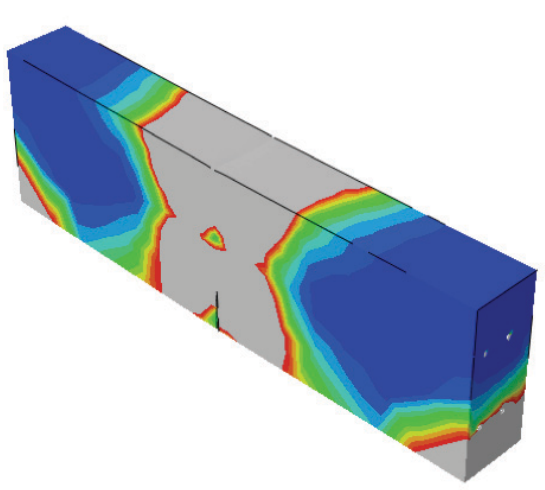

(c)

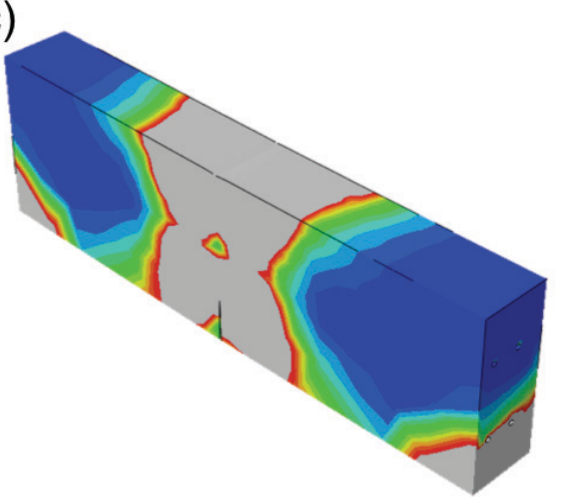

(d)

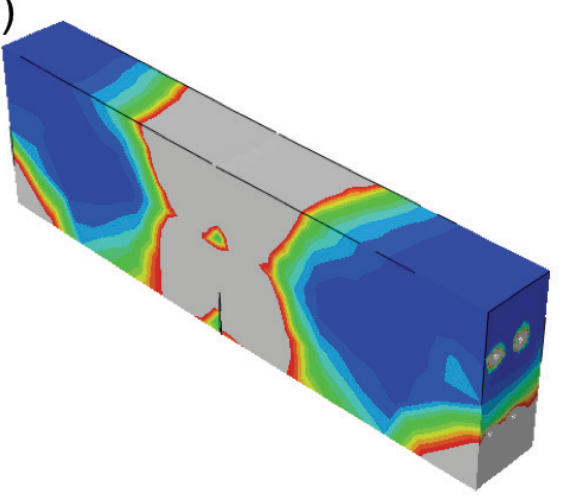

Figure 7 Plastic strain (gray regions) in the matrix of the three-point bending beam with non-pre-strained SMA wires (a) after loading and (b) after heating and with $1.6 \%$ pre-strained SMA wires (c) after loading and (d) after heating to $442 \mathrm{~K}$. The total volume of plasticity in the matrix is different by only about $1 \%$ between the pre-strained and non-pre-strained cases after heating.

To overcome the plasticity and achieve a complete crack closure, we hypothesize that pre-straining the SMA wires could have a significant impact and simulate several cases here. The modeling method for pre-strained wire is discussed in Section 3.4. In this section, the results of the same configuration with no prestrain, $1.6 \%$ and $2.6 \%$ pre-strain in the SMA wires is compared, respectively. 
As illustrated in Figure 8, the pre-strain plays a significant role in promoting the crack closure, which will ultimately facilitate self-healing. With a larger prestrain, the final crack opening displacement becomes smaller. In the three-point bending sample with a $2.6 \%$ pre-strain, the final COD reaches zero, which implies that the crack is fully closed after healing. In addition to the COD, the oriented martensitic volume fraction during the loading steps is displayed in Figure 9 (a) and (b), with a comparison to the one without pre-strain (Figure 9 (c) and (d)). In particular, the volume fraction of the oriented martensite in an SMA element located in the vicinity of crack tip (in the middle of a bottom wire) under varying pre-strain conditions is recorded and presented in Figure 10. The results clearly illustrate that by applying a pre-strain, the oriented martensite after loading is significantly higher than the one without pre-strain, while after heating it turns to zero in both cases. In the SMA with pre-strain, there is an initial fraction of oriented martensite, which is further accumulated upon loading, and then during the heating stage, the entire fraction of oriented martensite is transformed to austenite. The larger the pre-strain, the higher the initial fraction of oriented martensite, and the more deformation that can be recovered to close the crack and overcome plastic strain. Therefore, prestrain in the SMA wires appears vital for improving the crack closure of the composites. It is noted that an additional mechanism to apply "pre-strain" in situ would be to have poor bonding between the matrix and SMA and a low fracture strain for the matrix. In this manner, the matrix would fracture at a low applied load, the SMA would bridge the crack and debond from the matrix for some significant length of the wire surrounding the crack. Meanwhile, the SMA itself would also 
undergo a significant strain (similar to a pre-strain) in the wire during continued loading. This strain would then act as a pre-strain in the wire to pull the bridged crack back together upon heating. However depending on the amount of plasticity induced in the matrix and wires, this kind of pre-strain alone may not be sufficient to close the crack faces completely.

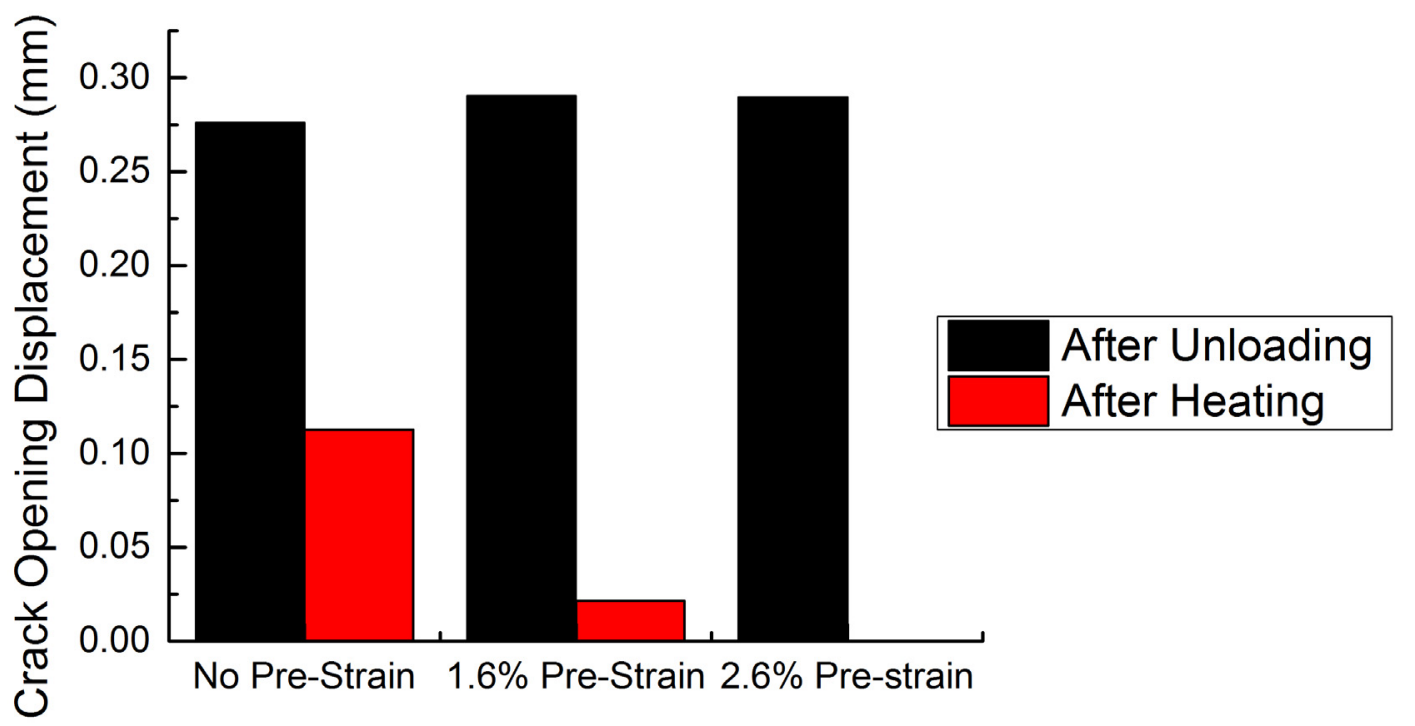

Figure 8 Crack opening displacement after heating in the three-point bending beam with varying pre-strains in SMA. The COD for the $2.6 \%$ pre-strained sample reaches zero after heating. 
(a) After loading; with pre-strain
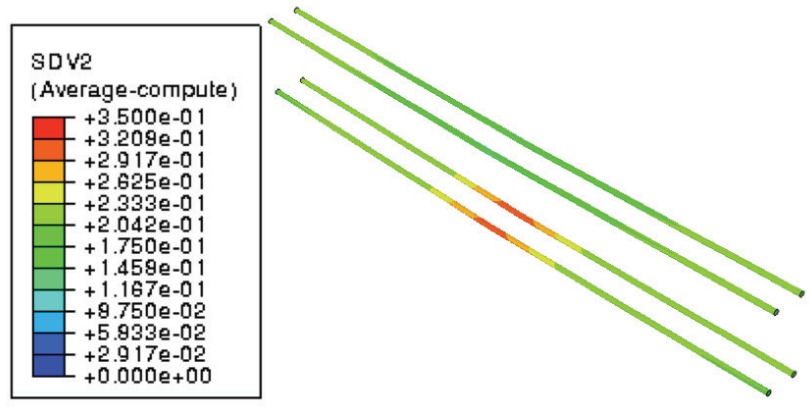

(c) After loading; without pre-strain

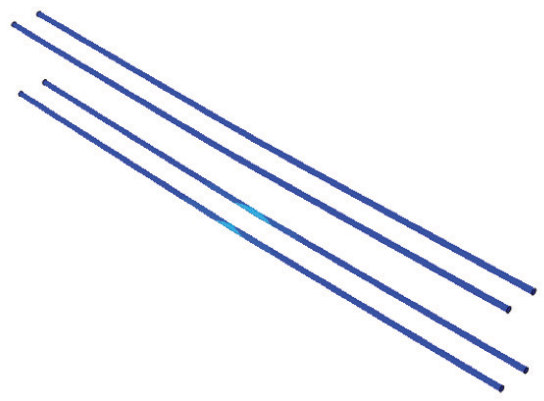

(b) After heating; with pre-strain

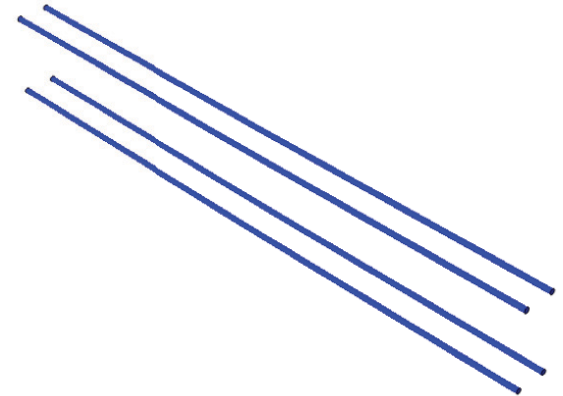

(d) After heating; without pre-strain

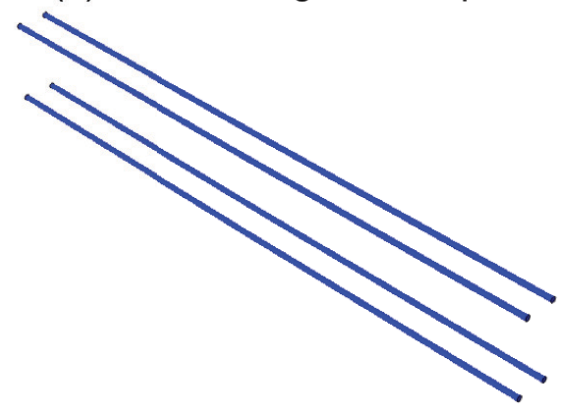

Figure 9 Distributions of oriented martensite volume fraction in the SMA wires after loading $(a, c)$ and after heating $(b, d)$ with $1.6 \%$ pre-strain $(a, b)$ and without pre-strain (c,d). 


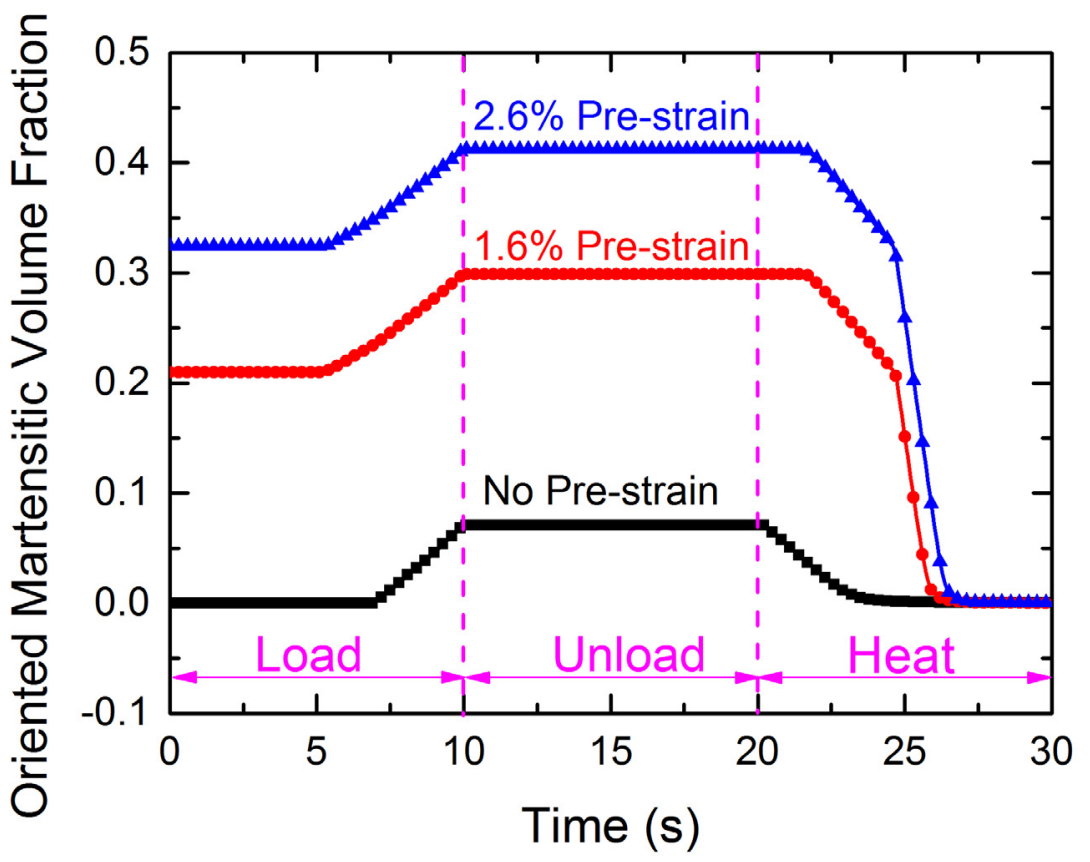

Figure 10 Volume fraction of oriented martensite during loading with varying pre-strains in an SMA element in the vicinity of crack

\section{Conclusions}

In this paper, a proposed liquid-assisted SMA self-healing technology is realized by utilizing a modeling method in the finite element software Abaqus. Three-dimensional self-healing SMA-reinforced composites are modeled and simulated by adopting a 3D SMA constitutive model that accounts for elasticity, orientation, reorientation and plasticity. A modeling approach dealing with composites with pre-strained SMA wires is also developed to further improve the self-healing effect. A composite structure simulating an experiment setup is run and the modeling methodology is thus validated via COD measurement and DIC data. Crack closure in the SMA-reinforced MMC structures is stressed from the modeling 
point of view, with an emphasis on the role of the SMA reinforcement, the softening property of the matrix, and the effect of pre-strain in the SMA. Results show that SMA wires are able to provide a clamping force to close the pre-crack in the composite samples. SMA reinforcement distinguishes itself from other metallic materials by exhibiting a stronger shape recovery ability. Moreover, using prestrained SMA reinforcement can significantly improve the healing capability. The softening property of the metallic matrix with higher temperature also promotes the self-healing of cracked composites.

An advantage of the three-dimensional modeling method developed in this paper is its easy and flexible implementation - no special element is needed for either composite or SMA. Furthermore, by using the developed user subroutine script VUMAT, the way of modeling a complex SMA-reinforced composite is fundamentally the same as modeling any two-material composite structure in Abaqus. It is simple to change the material property, pre-strain and initial martensitic volume fractions without modifying the geometry, even for pre-strained SMA wires. This flexibility of the modeling method enables design and optimization of the SMA-reinforced MMC to maximize the self-healing ability. Other factors such as local debonding of wires and matrix fracture will be considered in future work. It is noted that perfect bonding between reinforcement and matrix is assumed throughout the paper while some local debonding is inevitable in reality. The interfacial properties would have some impact on the results, as well as the effect of partial melting of matrix material at elevated temperatures. These studies can effectively provide both quantitative and qualitative guidance to develop a 
composite system with optimal SMA wire reinforcement to be used in aeronautics applications. 


\section{Acknowledgments}

This work was performed under the following financial supports of NASA

Aeronautics Research Mission Directorate (ARMD) through grant number

NNX13AR52A and Department of Energy through grant number DE-SC0010594.

\section{References}

Abaqus, 2010. Analysis User's Manual. Dassault Systems of America Corp. Araki, S., Ono, H., Saito, K., 2002. Micromechanical analysis of crack closure mechanism for intelligent material containing TiNi fibers - (2nd report, numerical calculation of stress intensity factor in the process of shape memory shrinkage of TiNi fibers). Jsme Int J a-Solid M 45, 356-362.

ASTM, 2000. Standard Test Method for Tension Testing of Metallic Materials. ASTM E8-00, Philadelphia, PA.

Belytschko, T., Liu, W.K., Moran, B., Elkhodary, K., 2013. Nonlinear finite elements for continua and structures. John Wiley \& Sons.

Bender, M.D., Olson, G.B., 2008. Computational Thermodynamics-Based Design of Nanodispersion-Strengthened Shape Memory Alloys. SMST-2007: Proceedings of the International Conference on Shape Memory and Superelastic Technologies, 115122.

Blaiszik, B.J., Kramer, S.L.B., Olugebefola, S.C., Moore, J.S., Sottos, N.R., White, S.R., 2010. Self-Healing Polymers and Composites. Annu Rev Mater Res 40, 179-211.

Bor, T.C., Warnet, L., Akkerman, R., de Boer, A., 2010. Modeling of Stress Development During Thermal Damage Healing in Fiber-reinforced Composite Materials Containing Embedded Shape Memory Alloy Wires. J Comp Mat 44, 25472572.

Brinson, L.C., 1993. One-dimensional constitutive behavior of shape memory alloys: thermomechanical derivation with non-constant material functions and redefined martensite internal variable. J Intel Mat Syst Str 4, 229-242.

Burton, D.S., Gao, X., Brinson, L.C., 2006. Finite element simulation of a self-healing shape memory alloy composite. Mech Mater 38, 525-537.

Chen, H., Ma, X., Wu, S.F., Tian, H., 2014. A Rapidly Self-Healing Supramolecular Polymer Hydrogel with Photostimulated Room-Temperature Phosphorescence Responsiveness. Angew Chem Int Edit 53, 14149-14152.

Chen, X.X., Dam, M.A., Ono, K., Mal, A., Shen, H.B., Nutt, S.R., Sheran, K., Wudl, F., 2002. A thermally re-mendable cross-linked polymeric material. Science 295, 1698-1702. Ferguson, J.B., Schultz, B.F., Rohatgi, P.K., 2015. Zinc alloy ZA-8/shape memory alloy self-healing metal matrix composite. Mat Sci Eng a-Struct 620, 85-88. 
Files, B., Olson, G.B., 1997. Terminator 3: biomimetic self-healing alloy composite, Proceedings of the 2nd Internatioal Conference on Shape Memory \& Superelastic Technologies, pp. 281-286.

Fisher, C.R., Wright, M.C., Wallace, T.A., Manuel, M.V., 2013. Design methodology for liquid-assisted self-healing metals, ICSHM 2013: Proceedings of the 4th

International Conference on Self-Healing Materials, Ghent, Belgium, June 16-20, 2013. Ghent University; Delft University of Technology.

Fremond, M., 1996. Shape memory alloy. Springer.

Ghosh, S.K., 2009. Self-healing materials: fundamentals, design strategies, and applications. Wiley WCH, Weinheim.

Kawai, M., Ogawa, H., Baburaj, V., Koga, T., 1999. Micromechanical analysis for hysteretic behavior of unidirectional TiNiSMA fiber composites. J Intel Mat Syst Str 10, 14-28.

Lee, H.J., Lee, J.J., 2000. A numerical analysis of the buckling and postbuckling behavior of laminated composite shells with embedded shape memory alloy wire actuators. Smart Mater Struct 9, 780-787.

Madhan, M., Prabhakaran, G., 2012. Self-healing Ability of Structural Ceramics - A Review. Comm Com Inf Sc 330, 466-474.

Manuel, M.V., Olson, G.B., 2007. Biomimetic self-healing metals, Proceedings of 1st International Conference on Self-Healing Materials, Noordwijik aan Zee, The Netherlands, pp. 18-20.

Marfia, S., Sacco, E., Reddy, J.N., 2003. Superelastic and shape memory effects in laminated shape-memory-alloy beams. Aiaa J 41, 100-109.

Nosonovsky, M., Rohatgi, P.K., 2011. Biomimetics in materials science: self-healing, self-lubricating, and self-cleaning materials. Springer Science \& Business Media.

Panico, M., Brinson, L.C., 2007. A three-dimensional phenomenological model for martensite reorientation in shape memory alloys. J Mech Phys Solids 55, 2491-2511. Peng, X.H., Chen, B., Chen, X., Wang, J., Wang, H.Y., 2012. A Constitutive Model for Transformation, Reorientation and Plastic Deformation of Shape Memory Alloys. Acta Mech Solida Sin 25, 285-298.

Popov, P., Lagoudas, D.C., 2007. A 3-D constitutive model for shape memory alloys incorporating pseudoelasticity and detwinning of self-accommodated martensite. Int J Plasticity 23, 1679-1720.

Rebillat, F., 2014. Advances in self-healing ceramic matrix composites. Woodh Pub S Compos S, 369-409.

Ruggles-Wrenn, M.B., Pope, M.T., 2014. Creep Behavior in Interlaminar Shear of a $\mathrm{SiC} / \mathrm{SiC}$ Ceramic Composite with a Self-healing Matrix. Appl Compos Mater 21, 213225.

Sharma, A.K., Harursampath, D.K., 2008. Variational Asymptotic Analysis of a Selfhealing SMA Composite.

Stebner, A.P., Brinson, L.C., 2013. Explicit finite element implementation of an improved three dimensional constitutive model for shape memory alloys. Comput Method Appl M 257, 17-35.

White, S.R., Sottos, N.R., Geubelle, P.H., Moore, J.S., Kessler, M.R., Sriram, S.R., Brown, E.N., Viswanathan, S., 2001. Autonomic healing of polymer composites. Nature 409, 794-797. 
Wright, M., Manuel, M., Wallace, T., 2013. Fatigue Resistance of Liquid-assisted Selfrepairing Aluminum Alloys Reinforced with Shape Memory Alloys.

Wu, D.Y., Meure, S., Solomon, D., 2008. Self-healing polymeric materials: A review of recent developments. Prog Polym Sci 33, 479-522.

Zak, A.J., Cartmell, M.P., Ostachowicz, W.M., Wiercigroch, M., 2003. One-dimensional shape memory alloy models for use with reinforced composite structures. Smart Mater Struct 12, 338-346.

Zhu, P., Stebner, A.P., Brinson, L.C., Finite element study of pore interactions in shape memory alloy plates using an elastic-transformation-plastic constitutive model, ASME 2013 conference on smart materials, adaptive structures and intelligent systems, Snowbird, Utah.

Zhu, P., Stebner, A.P., Brinson, L.C., 2014. Plastic and transformation interactions of pores in shape memory alloy plates. Smart Materials and Structures 23, 104008. 